\title{
Modified Misgav Ladach Method versus Pfannenstiel Kerr Method in Women with Previous Cesarean Section: a Randomized Controlled Trial
}

\author{
Ahmed Elnaggar ${ }^{*}$, Mohamed Abdel-Hafeez ${ }^{1}$, GamalFarag Mostafa $^{1}$ and Mohamed Abdelghani Abdelaziz ${ }^{1}$ \\ ${ }^{1 *}$ Department of Obstetrics Gynecology, Ain Shams University, Cairo, Egypt
}

Received: December 14, 2015; Accepted: August 16, 2016; Published: August 25, 2016

*Corresponding author: Ahmed Elnaggar, Department of Obstetrics and Gynecology, Jersey General Hospital, Gloucester Street, St Helier, Jersey, United Kingdom, Tel: +44 (0) 1534 442000; Email: a.elnaggar@health.gov.je

\begin{abstract}
Objective: To compare Modified Misgav Ladach Method (MMLM) versus Pfannenstiel-Kerr Method (PKM) regarding intraoperative and short-term postoperative outcomes.

Background: Cesarean section is considered as the most common major abdominal operation in women.Various abdominal incisions have been applied for cesarean delivery.

Materials and methods: The current prospective randomized trial involved 264 women undergoing transverse lower uterine segment cesarean section at Ain-shams University Hospital, Cairo, Egypt, between August 2012 and February 2013. 132 allocated to MMLM group and 132 allocated to PKM group. Main outcome measures were: the total operative time of surgery, time until delivery of neonate (extraction time), Apgar score, blood loss, and the number of suture packets used.
\end{abstract}

Results: MMLM was performed in 128 women and while, PKM was performed in 126 women (ten women withdrew from the study). The main obstetrical characteristics of both groups were similar as regard maternal age, weight, height, body mass index. Both groups were also similar as regard the type of employed anesthesia $(p>$ $0.05)$. In the current study there was a significant reduction in total operative time and extraction time $(p<0.001)$ in MMLM compared with PKM. In addition, there was a statistical difference between both group regarding number of sutures packets used $(p<0.001)$.

Conclusion: MMLM significantly reduced the total operative time and extraction time compared to the PKM. Moreover, MMLM significantly reduced the number of used sutures compared to the PKM. . It is likely to be more cost-effective.

Keywords: Modified Misgav-Ladach technique; Cesarean Section; Pfannenstiel-Kerr incision

\section{Introduction}

Cesarean section is considered as the most common major abdominal operation in women. Over the past century, the rate of delivery by cesarean section has been increased all-over the world [1]. The over-all worldwide cesarean section rate is $15 \%$, ranging from $3.5 \%$ in Africa to $29.2 \%$ in Latin America and the Caribbean [2]. There is no universal surgical technique for cesarean section. The wide variation in surgical techniques in practice can be attributed to many factors namely the clinical situation and the preference of the surgeon [3]. Various abdominal incisions have been applied for cesarean delivery [3]. They include transverse incision (Pfannenstiel, Maylard, Cherney and Joel-Cohen) and vertical incision (midline and para median) [3]. All-over the world, the transverse suprapubic skin incision is the most common technique performed for cesarean section followed by Pfannenstiel incision and Joel-Cohen abdominal incision. Pfannenstiel authenticated the Pfannenstiel incision in 1900; it is a horizontal skin incision about $2 \mathrm{~cm}$ above pubic symphysis [4].

Joel-Cohen created an incision for abdominal hysterectomy in 1954; nevertheless, obstetricians have since used this widely to do cesarean section [5]. The incision is a straight horizontal incision, being performed slightly higher than the Pfannenstiel incision, about $3 \mathrm{~cm}$ below the line joining the anterior superior iliac spines. In order to simplify the surgical procedure and minimize the tissue trauma, the Joel-Cohen method was modified by Stark and coworkers at Misgav Ladach General Hospital in Jerusalem, to create modified Misgav Ladach method (MMLM) [6]. The main criteria of the modified Misgav Ladach technique for cesarean section were authenticated to be the transverse incision using Joel-Cohen incision for opening the abdomen, suturing the uterus in one layer and non closure of the visceral and parietal peritoneum [6]. The aim of the current study was to compare MMLM versus Pfannenstiel-Kerr Method (PKM) in reducing total operation time and operation related morbidity of cesarean section in women with previous one cesarean delivery. Materials and Methods

The current randomized controlled clinical trial was conducted at Ain-shams University Hospital, Cairo, Egypt, between August 2012 and February 2013, after being approved by the ethical committee of obstetrics and gynecology department Ain-shams 
University. The study aim and procedures were authenticated to all enrolled women and a written informed consent was obtained from each women. Random sequence was performed using a computer-generated randomization plan; and allocation concealment was done using a computer based sealed opaque envelope method. The type of incision was printed on identical sheets of paper and put into similar consecutively numbered sealed opaque envelopes by a non-participating doctor. Just before the incision of the skin, the circulating nurse opened the envelope.

Women with 38 weeks of gestation or more determined by sure date of last menstrual period or by serial ultrasound in uncertain dates with previous one cesarean with or without history of vaginal deliveries and had no uterine contractions were only included in the current study. Women who had two or more previous cesarean section, previous other abdominal operation, anemia, bleeding disorders, intra-partum febrile illness, placenta previa, abruptio placentae, severe preeclampsia, multiple pregnancies and an antibiotic use in the previous two weeks were excluded from the study.

Each participant underwent history taking, physical examination and certain investigations as preoperative hemoglobin, preoperative haematocrit value. Women were allocated to one of the two arms: 132 to the MMLM technique and 132 to the PKM). Main outcome measures were, the total operative time of surgery, time until delivery of neonate (extraction time), Apgar score, blood loss, and the number of used sutures. Additional outcomes evaluated were return of bowel restitution, febrile morbidity, wound complications, the need for analgesics in the first 6 hours, total analgesic dose in the first 24 hours, the score obtained on Visual Analog Scale (VAS) at 6 and 24 hours of the operation, time to mobilization, time to oral intake and time to breastfeeding initiation.

All operations were performed by two experienced surgeons each of whom performed at least 80 first time and 20 repeat cesarean sections using both techniques.

\section{The Surgical Methods}

\section{The modified Misgav Ladach method}

- The skin was incised through transverse Pfannenstiel skin incision. The subcutaneous tissue was then incised and bluntly divided.

- The fascia was transversely incised $3 \mathrm{~cm}$ and bluntly divided.

- The parietal and visceral peritoneum was opened bluntly in vertical direction.

- The uterus sharply opened in superficial layer, the deep layer were sharply opened and extended bluntly.

- The fetus was then delivered and the placenta was left for spontaneous separation.

- The uterus was closed with a single-layer locking no 1 polyglactin 910 suture using additional haemostatic stitches if required.
- The visceral and parietal peritoneum left unsutured.

- The subcutaneous tissue left unsutured.

- The skin was closed with continuous subcuticular polyglactin 910 sutures [6].

\section{The Pfannenstiel Kerr method}

- The skin was incised through transverse Pfannenstiel skin incision. The subcutaneous tissue was then incised and sharply divided with scissors.

- The fascia was transversely incised $15 \mathrm{~cm}$.

- The parietal and visceral peritoneum was opened sharply in vertical direction.

- The uterine opening the same as in MMLM.

- The fetus was then delivered and the placenta was left for spontaneous separation.

- The uterus was closed with a two-layer continuous no 1 polyglactin 910 suture using additional hemostatic stitches if required.

- The visceral and parietal peritoneum was closed with a continuous polyglactin 910 suture.

- The subcutaneous tissue was not sutured.

- The skin was closed with continuous subcuticular polyglactin 910 sutures [6].

The type of anesthesia employed was decided by the anesthesiologist on call, without knowledge of the study arm that women were allocated to.

Prophylactic antibiotics were administered to all women after umbilical cord clamping in the form of flucloxacillin, amoxicillin (Flumox $^{\mathrm{TM}}$, EPICO) 2 grams intravenously.

Extraction time was defined as the interval from skin incision to the clamping of the umbilical cord, while the total operative time was defined as the time from skin incision to the end of the skin closure. Total operative and extraction times were recorded by an independent doctor using stopwatch.

Blood loss was estimated by the difference in hemoglobin levels and haematocrit value before and after the operation and by calculated estimated blood loss derived by multiplying the calculated maternal blood volume by the percent of blood volume lost, where calculated maternal blood volume $=0.75 \mathrm{X}\{[$ maternal height in inches X 50]+[maternal weight in pounds X 25]\} and percent of blood volume lost $=($ preoperative haematocrit postoperative haematocrit\}/preoperative haematocrit] [7]. Wound complications were evaluated on the fourth and fifteenth postoperative day, these included wound infection with purulent discharge, wound seroma; which is defined as a pocket containing serous fluid. Pain was assessed by $10 \mathrm{~cm}$ visual analog scale at 6 and 24 hours after the operation. It consists of a $10 \mathrm{~cm}$ line with two end-points representing 'no pain' and 'worst pain imaginable'. Patients are asked to classify their pain by placing a mark on the line corresponding to their current 
level of pain. Analgesic requirements, antibiotic use, and day of bowel restitution were registered from the hospital notes and confirmed with patients on the second postoperative day. Febrile morbidity was defined as axillary temperature more than $38^{\circ} \mathrm{C}$ persisting for more than 48 hours.

\section{Sample size justification}

On the basis of a previously published article the total operation time by traditional PKM of cesarean section was about 33 minutes [8] and our aim is to reduce the total operative time by MMLM to 17 minutes, so we have to include 126 women in each arm of our randomized trial to detect such difference at $80 \%$ power and type I error 0.05 using PS Power and Sample Size Program version 3.0.43 and to nullify the attrition error we added 13 patients so the total sample size will be 265 subjects.

\section{Statistical analysis}

Statistical analysis was done on a personal computer using IBM(C) SPSSC) version 21 (IBM(C) Corp., Armonk, NY). Since these data are skewed, they were presented as median and interquartile range and between-group differences are compared non-parametrically using the Mann Whitney U test. Qualitative data are presented as number and percentage and differences between groups are compared using the Pearson chi square test or the chi square test for trends for nominal or ordinal data respectively. Fisher's exact test is used in place of the chi square test if $>20 \%$ of cells in any contingency table has an expected count of $<5$. All $\mathrm{P}$ values are two-sided. $\mathrm{P}<0.05$ is considered statistically significant.

\section{Results}

A total of 264 women were recruited to the study, 132 allocated to MMLM group and 132 allocated to PKM group. Ten women $(3.7 \%)$ were excluded from the study because it was not possible to contact them after discharge from hospital ( 6 women in MMLM group and 4 women in PKM group). Accordingly MMLM was performed in $50.4 \%(n=128)$ and PKM was performed in $49.6 \%(n=126)$.

The main obstetrical characteristics of both groups were similar as regard maternal age, weight, height, body mass index $(\mathrm{kg} / \mathrm{m} 2)(p>0.05)$ (Table 1).The neonates delivered by MMLM or PKM had similar birth weights and gestational ages at delivery (Table 1)

Both groups were also similar as regard the type of employed anesthesia $(p>0.05)$. In the current study there was a significant reduction in total operative time and extraction time $(p<0.001)$ in MMLM compared with PKM (Table 1 and 2). There were no statistical significant differences between both group regarding wound complications and postoperative fever while there was a statistical difference between both group regarding number of sutures packets used $(p<0.001)$ (Table 2$)$.

\section{Discussion}

The current study authenticated that, MMLM significantly reduced the total operative time and extraction compared to the PKM $(p<0.001)$. Moreover, MMLM significantly reduced the
Table 1: Comparison of the two study groups: Quantitative variables

\begin{tabular}{|c|c|c|c|c|c|}
\hline & \begin{tabular}{|l} 
MMLM $^{1}$ \\
group
\end{tabular} & $(n=128)$ & $\begin{array}{l}\text { PKM }^{2} \\
\text { group }\end{array}$ & $(n=126)$ & \\
\hline Variable & Median & $\mathrm{IQR}^{3}$ & Median & $\mathrm{IQR}^{3}$ & $P$ value \\
\hline Age (years) & 26.0 & $24-30$ & 27.0 & $24-30$ & 0.147 \\
\hline Weight (kg) & 79.5 & $72-84.8$ & 78.0 & $72-86$ & 0.693 \\
\hline Height (cm) & 158.0 & $156-160$ & 158.0 & $156-160$ & 0.529 \\
\hline BMI (kg/m2) & 32.0 & $29.6-34.4$ & 32.0 & $29-34.8$ & 0.625 \\
\hline $\begin{array}{l}\text { Gestational age } \\
\text { (week) }\end{array}$ & 38.0 & $37-39$ & 38.0 & $37-39$ & 0.824 \\
\hline $\begin{array}{l}\text { Preoperative } \\
\text { hemoglobin (g/ } \\
\text { dl) }\end{array}$ & 10.5 & $10-11$ & 10.5 & $10-10.9$ & 0.988 \\
\hline $\begin{array}{l}\text { Preoperative } \\
\text { hematocrit (\%) }\end{array}$ & 30.2 & $29.5-31$ & 30.2 & 29.5 & 0.347 \\
\hline Operative time & 45.0 & $40-50$ & 52.0 & 45.0 & $<0.001$ \\
\hline $\begin{array}{l}\text { Fetal extraction } \\
\text { time (min) }\end{array}$ & 4.0 & $3.6-4.3$ & 8.1 & 7.7- 8.6 & $<0.001$ \\
\hline Blood loss (ml) & 280.1 & 235- 333 & 292.5 & $245-357$ & 0.200 \\
\hline $\begin{array}{l}\text { Apgar score at } \\
1 \mathrm{~min}\end{array}$ & 7.0 & $7-7$ & 7.0 & $7-7$ & 0.458 \\
\hline $\begin{array}{l}\text { Apgar score at } \\
5 \mathrm{~min}\end{array}$ & 9.0 & $9-9$ & 9.0 & $9-9$ & 0.843 \\
\hline $\begin{array}{l}\text { VAS }^{4} \text { score at } 6 \\
\text { hours }\end{array}$ & 4.0 & 3.3- 5 & 4.0 & 3- 4 & 0.673 \\
\hline $\begin{array}{l}\text { VAS }^{4} \text { score at } 12 \\
\text { hours }\end{array}$ & 7.0 & 6- 8 & 7.0 & $6-8$ & 0.597 \\
\hline $\begin{array}{l}\text { Number of } \\
\text { analgesic doses } \\
\text { in } 1 \text { st } 6 \text { hours }\end{array}$ & 1.0 & $1-2$ & 1.0 & $1-2$ & 0.237 \\
\hline $\begin{array}{l}\text { Number of } \\
\text { analgesic doses } \\
\text { in 1st } 24 \text { hours }\end{array}$ & 4.0 & $3-5$ & 4.0 & $3-5$ & 0.412 \\
\hline $\begin{array}{l}\text { Time to } \\
\text { mobilization } \\
\text { (hours) }\end{array}$ & 6.0 & $4-7$ & 6.0 & $4-7$ & 0.751 \\
\hline $\begin{array}{l}\text { Time to bowel } \\
\text { restitution } \\
\text { (hours) }\end{array}$ & 7.0 & $5-8$ & 6.5 & $5-9$ & 0.721 \\
\hline $\begin{array}{l}\text { Time to oral } \\
\text { feeding (hours) }\end{array}$ & 7.0 & $4.3-9$ & 8.0 & $5-8$ & 0.319 \\
\hline $\begin{array}{l}\text { Postoperative } \\
\text { hemoglobin (g/ } \\
\text { dl) }\end{array}$ & 9.9 & $9.4-10.3$ & 9.8 & $9.3-10.3$ & 0.519 \\
\hline $\begin{array}{l}\text { Drop in } \mathrm{Hb}^{5}(\mathrm{~g} / \\
\mathrm{dl})\end{array}$ & 0.6 & $0.5-0.7$ & 0.6 & $0.5-0.8$ & 0.084 \\
\hline $\begin{array}{l}\text { Postoperative } \\
\text { hematocrit (\%) }\end{array}$ & 28.9 & $28.1-29.7$ & 29.0 & $28.2-9.8$ & 0.581 \\
\hline $\begin{array}{l}\text { Drop in } \\
\text { hematocrit (\%) }\end{array}$ & 1.3 & $1.0-1.5$ & 1.3 & $1.1-1.6$ & 0.199 \\
\hline $\begin{array}{l}\text { Baby's weight } \\
(\mathrm{kg})\end{array}$ & 3.0 & $3-4$ & 3.0 & $3-4$ & 0.811 \\
\hline
\end{tabular}


Table 2: Comparison between the two study groups: Qualitative data $^{1}$

\begin{tabular}{|c|c|c|c|}
\hline Variable & $\begin{array}{l}\text { MMLM }^{2} \text { group } \\
(\mathrm{n}=128)(\mathrm{N} \\
\%)\end{array}$ & $\begin{array}{l}\text { PKM group }^{3} \\
(n=126)(N \%)\end{array}$ & P value \\
\hline Anesthesia & & & 0.884 \\
\hline Spinal & $82(64.1 \%)$ & $79(62.7 \%)$ & \\
\hline General & $42(32.8 \%)$ & $44(34.9 \%)$ & \\
\hline Combined spinal/general & $4(3.1 \%)$ & $3(2.4 \%)$ & \\
\hline $\begin{array}{l}\text { Number of suture } \\
\text { packets }\end{array}$ & & & $<0.001$ \\
\hline Three & $94(73.4 \%)$ & $40(31.7 \%)$ & \\
\hline Four & $32(25.0 \%)$ & $67(53.2 \%)$ & \\
\hline Five & $1(0.8 \%)$ & $16(12.7 \%)$ & \\
\hline Six & $1(0.8 \%)$ & $2(1.6 \%)$ & \\
\hline Seven & $0(0 \%)$ & $1(0.8 \%)$ & \\
\hline Postoperative fever & & & 1.000 \\
\hline $\begin{array}{l}\text { Positive Postoperative } \\
\text { fever }\end{array}$ & $2(2.3 \%)$ & $2(1.6 \%)$ & \\
\hline No postoperative fever & 125 (97.7\%) & 124(98.4\%) & \\
\hline Wound complications & & & 0.449 \\
\hline Nil & 125 (97.7\%) & $121(96.0 \%)$ & \\
\hline Seroma & $2(1.6 \%)$ & $3(2.4 \%)$ & \\
\hline Infection & $1(0.8 \%)$ & $2(1.6 \%)$ & \\
\hline
\end{tabular}

number of used sutures compared to the PKM $(p<0.001)$. These findings were similar to all previous trials which demonstrated statistically significant reduction in operative time and extraction time with MMLM $[1,6,9]$. In Cochrane reviews discussing technique for cesarean section, Joel Cohen-based techniques (Joel Cohen, Misgav Ladach and modified Misgav Ladach) were authenticated to have several advantages over Pfannenstiel and traditional cesarean section methods [10].

The reduction in total operative time in the MMLM is reached via removal of each redundant step in the traditional PKM. One-layer suturing the uterus is delineated to result in better haemostatic, less operative time, less infectious morbidity than the two-layer closure However, there is still some debates regarding its impact on the next pregnancy, with some studies demonstrating a similar rate of uterine dehiscence [11,12,13] and one study authenticating a higher rate than the two-layer closure [14].

In the study by Naki, et al. which compared the Misgav Ladach Method (MLM) and PKM and the study by Gedikbasi, et al. which compared the MMLM and PKM, the myometrial incision was closed in single layer in both groups (MLM and MMLM and the total operative time was significantly shorter in the MLM and MMLM than in the PKM $[6,15]$. MLM being a faster method of cesarean section is associated with benefits of the method in the case of emergency caesarean section compared to elective surgery [16]. Moreover, less time spent in the operating room enables the obstetric team to spend more time in the labor ward, particularly in overcrowded and inadequately staffed labor wards [17]. Also, the reduction in operative time was authenticated to be associated with economic advantages due to less suture costs, less anesthesia needs, and a shorter hospitalization [18,19]. Our data were consistent with previous reports regarding the reduction in the number of used sutures with the MLM and MMLM $(p<0.001)[6,15]$. MLM and MMLM were reported to decrease blood loss in cesarean section in comparison to the conventional Pfannenstiel incision [18,19]. Indeed, the difference between pre- and postoperative hemoglobin levels has been recorded to be similar in women undergoing either MLM and its modification or PKM in the current and other studies [6,15].

There was no statistically significant difference between both groups as regard time of bowel restitution, time to oral intake, and time to mobilization $(p<0.05)$. These data were supported by other trials that showed no statistically significant difference between both techniques as regard these aspects [1,6]. In this study there was no difference between both groups as regard time to breastfeeding initiation $(p>0.05)$. We found no previous trials assessing the difference between the MMLM and PKM in the time to breastfeeding initiation; however, there was only one randomized trial by Mathai, 2002, which showed no difference between the Joel Cohen technique and the PKM in the time to breastfeeding initiation [17]. There was no difference between the two groups as regard fever and wound complications in terms of wound seroma and infection $(p>0.05)$. These results are comparable to the results by others $[1,6,15]$.

\section{Conclusion}

MMLM significantly reduced the total operative time and extraction compared to the PKM. Moreover, MMLM significantly reduced the number of used sutures compared to the PKM. . It is likely to be more cost-effective.

\section{References}

1. Xavier P, Ayres-De-Campos D, Reynolds A, Guimarães M, Costa-Santos C, Patrício B. The modified Misgav-Ladach versus the PfannenstielKerr technique for cesarean section: a randomized trial. ActaObstet Gynecol Scand. 2005;84(9):878-882.

2. Betrán AP, Merialdi M, Lauer JA, Bing-Shun W, Thomas J, Van Look $P$, et al. Rates of caesarean section: analysis of global, regional and national estimates. PaediatrPerinatEpidemiol. 2007;21(2):98-113.

3. Mathai M, Hofmeyr GJ. Abdominal surgical incisions for cesarean section. Cochrane Database Syst Rev. 2007,24;(1):CD004453.

4. Stark M, Chavkin Y, Kupfersztain C, Guedj P, Finkel AR. Evaluation of combinations of procedures in Caesarean section. International J Gynecol Obstet. 1995;48(3):273-276.

5. Stark M, Finkel A. The comparison between the Joel Cohen and Pfannenstiel incisions in Caesarean section. European J Obstet Gynecol ReprodBiol. 1994;53(2):121-122.

6. Gedikbasi A, Akyol A, Ulker V, Yildirim D, Arslan O, Karaman E, et al. Cesarean techniques in cases with one previous cesarean delivery: comparison of modified Misgav-Ladach and Pfannenstiel-Kerr. Arch Gynecol Obstet. 2011;283(4):711-716. 
7. Leveno KJ, Cunningham FG, Gant NF, et al: In: Syder A, Loeb M, Boyle PJ, eds. Williams manual of obstetrics. 1st ed. New York, McGraw-Hill; 2003.192-194.

8. Franchi M, Ghezzi F, Raio L, Di Naro E, Miglierina M, Agosti M, et al. Joel-Cohen or Pfannenstiel incision at cesarean delivery: does it make a difference? ActaObstet Gynecol Scand. 2002;81:1040-1046.

9. Li M, Zou L, Zhu J. Study on modification of the MisgavLadach method for cesarean section. J Tongji Med Univ. 2001;21(1):75-77.

10. Björklund K, Kimaro M, Urassa E, Lindmark G. Introduction of the MisgavLadach caesarean section at an African tertiary centre: a randomised controlled trial. BJOG. 2000;107(2):209-216.

11. Tucker JM, Hauth JC, Hodgkins P, Owen J, Winkler CL. Trial of labor after a one- or two-layer closure of a low transverse uterine incision. Am J Obstet Gynecol. 1993;168(2):545-546.

12. Chapman SJ, Owen J, Hauth JC. One- versus two-layer closure of a low transverse cesarean: the next pregnancy. Obstet Gynecol. 1997;89(1):16-18

13. Durnwald C, Mercer B. Uterine rupture, perioperative and perinatal morbidity after single-layer and double-layer closure at cesarean delivery. Am J Obstet Gynecol. 2003;189(4):925-929.
14. Bujold E, Bujold C, Hamilton EF, Harel F, Gauthier RJ. The impact of a single-layer or double-layer closure on uterine rupture. Am J Obstet Gynecol. 2002;186(6):1326-1330.

15. Naki MM, Api O, Celik H, Kars B, Yașar E, Unal O. Comparative study of Misgav-Ladach and Pfannenstiel-Kerr cesarean techniques: a randomized controlled trial. J Matern Fetal Neonatal Med. 2011;24(2):239-244.

16. Kulas T, Habek D, Karsa M, Bobić-Vuković M. Modified MisgavLadach method for cesarean section: clinical experience. Gynecol Obstet Invest. 2008;65(4):222-226.

17. Mathai M, Ambersheth S, George A. Comparison of two transverse abdominal incisions for cesarean delivery. Int J Gynaecol Obstet. 2002;78(1):47-49.

18. Darj E, Nordström ML. The MisgavLadach method for cesarean section compared to the Pfannenstiel method. ActaObstet Gynecol Scand. 1999;78(1):37-41.

19. Wallin G, Fall O. Modified Joel-Cohen technique for caesarean delivery. Br J Obstet Gynaecol. 1999;106(3):221-226. 